\title{
Synthesis of novel hyper-cross-linked polymers as adsorbent for removing organic pollutants from humid streams
}

\author{
Wan-Qiu Wang ${ }^{\mathrm{a}}$, Junhui Wang ${ }^{\mathrm{b}}$, Jian-Gang Chen ${ }^{\mathrm{a}}$, Xiu-Shan Fan ${ }^{\mathrm{a}}$, Zhao-Tie Liu ${ }^{\mathrm{a}, *}$, Zhong-Wen Liu ${ }^{\mathrm{a}}$, \\ Jinqiang Jiang ${ }^{\mathrm{a}}$, Zhengping Hao ${ }^{\mathrm{b}, *}$ \\ ${ }^{a}$ Key Laboratory of Applied Surface and Colloid Chemistry, School of Chemistry E Chemical Engineering, Shaanxi Normal University, Xi'an 710119, China \\ ${ }^{\mathrm{b}}$ Research Center for Eco-Environmental Sciences, Chinese Academy of Sciences, Beijing 100085, China
}

\section{H I G H L I G H T S}

- A novel chlorine-containing HCP with higher surface area and hydrophobicity was synthesized.

- Hydrophobicity of HCP can be obtained by adjusting molar ratio of benzyl chlorine to FDA.

- The synthesized HCP-0.5 showed higher adsorption capability at room temperature for benzene.

- Existing of water vapor had little effect on dynamic adsorption capacity of benzene on HCP-0.5.

\section{A R T I C L E I N F O}

\section{Article history:}

Received 25 April 2015

Received in revised form 19 June 2015

Accepted 20 June 2015

Available online 25 June 2015

\section{Keywords:}

Hydrophobic HCPs

VOCs adsorption

Dynamic adsorption/desorption

Static adsorption/desorption

\begin{abstract}
A B S T R A C T
A new kind of hydrophobic hyper-cross-linked polymers (HCPs) with high surface area, large pore volume, and controllable average pore size was prepared. The synthesized HCP- 0.5 sample, having the biggest BET specific surface area $\left(1394 \mathrm{~m}^{2} / \mathrm{g}\right)$, pore volume $\left(1.55 \mathrm{~m}^{3} / \mathrm{g}\right)$ and micro-mesopore structure (average pore diameter of $4.4 \mathrm{~nm}$ ), was used as a novel adsorbent for removing benzene. The results of the static adsorption/desorption experiment at 298, 308 and $318 \mathrm{~K}$ showed that HCP-0.5 has a very large adsorption capability of $19.16 \mathrm{mmol} \mathrm{g}^{-1}$ at $298 \mathrm{~K}$ for benzene. Dynamic adsorption experiments of benzene on HCP-0.5 under dry and humid condition $(\mathrm{RH}=80 \%)$ revealed that the existence of water vapor had little effect on dynamic adsorption capacity of benzene on HCP-0.5 and almost did not change the breakthrough time. Therefore, these synthesized polymers can be used as efficient and competitive adsorbents for removing VOCs, especially under humid conditions.
\end{abstract}

(c) 2015 Elsevier B.V. All rights reserved.

\section{Introduction}

Volatile organic compounds (VOCs) such as benzene, toluene, trichloroethylene and methanol are emitted from a wide range of industries [1]. In addition to posing detrimental effects on human health, such as carcinogenic effects, emissions of some VOCs also contribute to stratospheric ozone depletion, formation of photochemical smog and a number of toxic byproducts [1,2]. Due to these negative effects, VOCs have already received great attention in the field of environmental control.

Among these VOCs removal methods such as condensation, adsorption, catalytic oxidation and incineration [3,4], the VOCs adsorption on porous adsorbents is regarded as an economical

* Corresponding authors. Tel.: +86 29 81530802; fax: +86 2981530811 (Z.-T. Liu). Tel.: +86 10 62923564; fax: +86 1062923564 (Z. Hao).

E-mail addresses: ztliu@snnu.edu.cn (Z.-T. Liu), zpinghao@rcees.ac.cn (Z. Hao). and effective treatment process [5]. Activated carbon as a facile adsorbent is applied extensively to remove VOCs from process effluent stream due to its high surface area, abundant porosity, sustainability and a relatively high adsorption capacity [6-9]. Nonetheless, activated carbon adsorption always encounters some problems such as finite pore volume, combustion and pore blocking [10]. Moreover, the hydrophilic nature of activated carbon limits its application on VOCs removal from humid gas streams, due to the competition of water vapor with organic species for adsorption sites on activated carbon and the slow adsorption kinetics of VOCs $[11,12]$. Therefore, it is significant to develop new adsorbent materials with hydrophobic nature as a potential alternative for activated carbon to remove VOCs from polluted air streams.

In the past few decades, as a promising adsorbent for removing VOCs from a wide range of gaseous streams [13-17], porous organic polymers (POPs), especially hyper-cross-linked polymers (HCPs) have been investigated extensively in gas adsorption due 
to its vast surface area, controllable pore structure, stable physical, chemical properties as well as low densities [18-20]. Moreover, hyper-cross-linked polymeric adsorbent without hydrophilic functional groups could possess a hydrophobic surface, which is beneficial for the removal of organic pollutants from humid gas streams.

In 2011, a versatile route to hyper-cross-linked polymers (HCPs) that avoids the need for monomers with specific polymerizable functionalities was demonstrated [21]. Li et al. used a simple one-step Friedel-Crafts reaction of a low-cost cross-linker with ordinary, low-functionality aromatic compounds as monomers to produce HCPs with high surface areas and large pore volumes. The major advantage of the new strategy is the wide range of monomers that are available. It provides a new approach for the synthesis of polymeric adsorbents with an excellent hydrophobic nature though selecting proper monomers.

In our previous paper [22], we synthesized a series of hyper-cross-linked polymers (HCPs) via a post-cross-linking reaction using low cross-linked polydivinylbenzene (PDVB) as precursor and 4,4'-bis(chloromethyl)biphenyl (BCMBP) as crosslinking reagent. The synthesized HCP-1.3 has high surface area, large pore volume and showed a good adsorption for benzene under water condition due to its high hydrophobic property. However, in our previous paper [22], we only studied the effect of the dynamic adsorption of benzene vapor containing 30\% water vapor, and did not investigate the dynamic adsorption behavior of benzene on HCP-1.3 under higher humid conditions. In the latest work [23], we synthesized a conjugated polymer adsorbent with pure carbon chain backbone, which had excellent hydrophobicity and higher adsorption capacity of benzene than activated carbon. To explore a novel hyper-cross-linked polymeric adsorbent with good adsorption capacity to remove VOCs from air streams, in the present paper, we synthesize a new kind of hydrophobic HCPs by Friedel-Crafts alkylation (as shown in Scheme 1). Benzyl chloride was used as a monomer to enhance the adsorption capacities of hyper-cross-linked polymeric adsorbents for adsorbing VOCs from humid gas stream. Various amounts of formaldehyde dimethyl acetal (FDA) were used as an external cross-linker to investigate the effect of the ratios of cross-linker to monomer on pore structure of the polymeric products. HCPs- 0.5 was selected as a model sample to investigate the adsorption property of the synthesized polymeric products. Benzene, one of the most common VOCs, was chosen as a representative adsorbate due to its high toxicity and volatility. Herein, static adsorption/desorption experiments at three different temperatures (298, 308 and $318 \mathrm{~K}$ ) and dynamic adsorption experiments under dry and humid conditions $(\mathrm{RH}=80 \%)$ of benzene on the synthesized polymeric product HCPs- 0.5 were investigated.

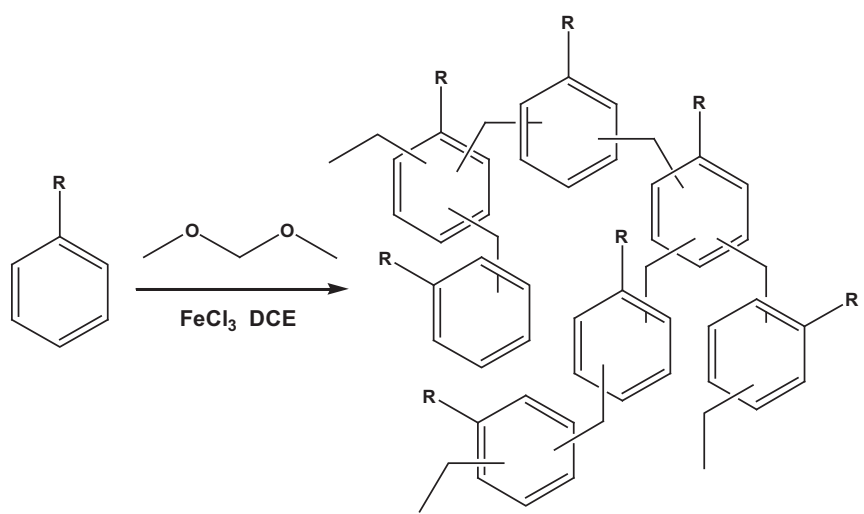

Scheme 1. Friedel-Crafts polymerization using formaldehyde dimethyl acetal.

\section{Experimental}

\subsection{Synthesis of HCPs}

Typically, $1.27 \mathrm{~g}$ benzyl chloride $(10 \mathrm{mmol})$ and $0.38 \mathrm{~g}$ formaldehyde dimethyl acetal (FDA, $5 \mathrm{mmol}$ ) were added to 1,2-dichloroethane (DCE, $20 \mathrm{~mL}$ ), followed by Iron (III) chloride (12 mmol). After stirring for $10 \mathrm{~min}$ at a room temperature, the mixture was heated to $45^{\circ} \mathrm{C}$ for $5 \mathrm{~h}$ and then heated to $80^{\circ} \mathrm{C}$ for $18 \mathrm{~h}$. The solid product was removed out and washed with methanol until the filtrate was clear, then further purified by soxhlet extraction in methanol for $12 \mathrm{~h}$ and dried in vacuo at $60^{\circ} \mathrm{C}$ for $18 \mathrm{~h}$. The resulting polymers were denoted as $\mathrm{HCP}-X$, where $X$ refers to the molar ratio of the cross-linker to the monomer. In this work, $0.5,1.0,1.5,2.0,2.5,3.0,3.5$ and 4.0 are selected as $X$ values, respectively.

\subsection{Characterizations}

Textural properties of each sample were investigated using a BEL SORP-max gas adsorption analyzer by nitrogen adsorption and desorption at liquid nitrogen temperature (77 K). Samples were degassed at $120^{\circ} \mathrm{C}$ for $12 \mathrm{~h}$ prior to analysis. Surface areas of samples were measured using the Brunauer-Emmett-Teller (BET) method. Pore size distributions of the porous materials were calculated using the density functional theory (DFT) method. The total pore volume was estimated from the amount adsorbed at a relative pressure of $\sim 0.99$. The micropore volume was calculated by a $t$-plot method. Transmission electron micrograph (TEM) was performed on a JEOL JEM-2100 instrument. High resolution scanning electron microscope micrographs (SEM) were performed on a Hitach S-4800 electron microscope, and the samples were sputter coated with platinum prior to measurement. Infrared spectra were collected on a Bruker Tensor 27 in the range of $400-4000 \mathrm{~cm}^{-1}$ using $\mathrm{KBr}$ disks. The thermal gravimetric analysis (TGA) was carried out on a TA Instruments Q600SDT thermal analyzer. The heating rate was $10^{\circ} \mathrm{C} \mathrm{min}-1$ from 25 to $1000^{\circ} \mathrm{C}$ under a nitrogen flow of $60 \mathrm{~mL} \mathrm{~min}^{-1}$.

\subsection{Static adsorption measurements}

The static adsorption experiments were carried out using an Intelligent Gravimetric Analyzer (IGA) supplied by Hiden Analytical Ltd. with a high sensitivity of $0.1 \mathrm{mg}$. This apparatus is an ultrahigh vacuum system, which allows isotherms and the corresponding kinetics of adsorption and desorption to be determined by setting various pressures. The microbalance has a long-term stability of $\pm 1 \mu \mathrm{g}$ with a weighing resolution of $0.2 \mu \mathrm{g}$. The sample $(60 \pm 1 \mathrm{mg})$ was degassed at a pressure of $<10^{-5} \mathrm{~Pa}$ at $393 \mathrm{~K}$ to remove the physically adsorbed impurities until it reached a constant weight. Pressure steps in the range of $p / p_{0}$ values from 0 to 0.98 were used to obtain the isotherm. The temperature of the sample was measured by a thermocouple that is located at $5 \mathrm{~mm}$ from the sample. The equilibrium uptake value was determined as being $90 \%$ of the predicted value, calculated in real time using the mass uptake profile. In the present work, 298, 308 and $318 \mathrm{~K}$ were selected as static adsorption temperatures, respectively. The saturated vapor pressures were calculated using the following equation [24]:

$\log _{10} p=A-\frac{B}{T+C}$

where $p$ is the saturated vapor pressure (mbar), $T$ is the temperature in $\left({ }^{\circ} \mathrm{C}\right)$ and $A, B$ and $C$ are constants defined by the adsorbate: benzene (281-403 K): $A=6.90565, B=1211.033, C=220.79$; water $(263-383 \mathrm{~K}): A=8.09553, B=1747.32, C=235.074$. 


\subsection{Dynamic adsorption measurements}

Dynamic adsorption measurements were carried out on a fixed-bed column. Detailed experimental conditions including the stock preparation of the analyte are corresponding with the experimental set-up and method described in our previous paper $[23,25]$. To reach and keep constant of the outlet concentration of benzene vapor, the flow rate of the carrier gas and the temperature of the saturator were adjusted. The benzene concentration was adapted to $530 \mathrm{ppm}$ and the total flow rate was $50 \mathrm{~mL} \mathrm{~min}{ }^{-1}$. Before starting each experiment, the samples were degassed at $100{ }^{\circ} \mathrm{C}$ for $24 \mathrm{~h}$ to remove the impurities. Then, approximate $60 \mathrm{mg}$ of sample was packed into a fixed-bed column (I.D. $6 \mathrm{~nm}$ ). Benzene vapor was selected as an adsorbate and the temperature was maintained at $298 \mathrm{~K}$. To investigate the effect of water vapor on the adsorption behavior, benzene with a concentration of $530 \mathrm{ppm}$ in a relative humidity $(\mathrm{RH})$ of $80 \%$ was passed through an adsorption column. The benzene concentrations in the feed and effluent streams were recorded on a gas chromatograph (GC) supplied by Agilent equipped with a flame ionization detector (FID) after being separated in an AB-GASPRO capillary column and the breakthrough curves were collected. The benzene adsorbed amounts by the sample which was packed in the column were calculated by the following equation [22]:

$Q=\frac{F_{A} t_{q}}{W}$

The time $t_{q}$ is estimated according to Eq. (3):

$t_{q}=\int\left(1-\frac{C_{o}}{C_{i}}\right) d t-t_{D}$

where $Q$ is the adsorbed amount $\left(\mathrm{mmol} \mathrm{g}^{-1}\right) ; F_{A}$ is the volumetric flow rate of the carrier gas $\left(\mathrm{mL} \mathrm{min}^{-1}\right) ; W$ is the net weight of adsorbent $\left(\mathrm{g}^{-1}\right) ; C_{i}$ represents the benzene concentration at the inlet $\left(\mathrm{g} \mathrm{mL}^{-1}\right)$, while $C_{o}$ is the benzene concentration at the outlet $\left(\mathrm{g} \mathrm{mL}^{-1}\right)$ and $t_{D}$ is the breakthrough time of the system (min).

\section{Results and discussion}

\subsection{Characterization of $H C P-X$}

A series of polymeric materials was prepared using benzyl chloride as a monomer and various amounts of FDA as a cross-linker. All products are brown-black insoluble powders. The $\mathrm{N}_{2}$ adsorption-desorption isotherms at $77 \mathrm{~K}$ over HCP-X samples are demonstrated in Fig. 1. It is observed that all the samples show a type I

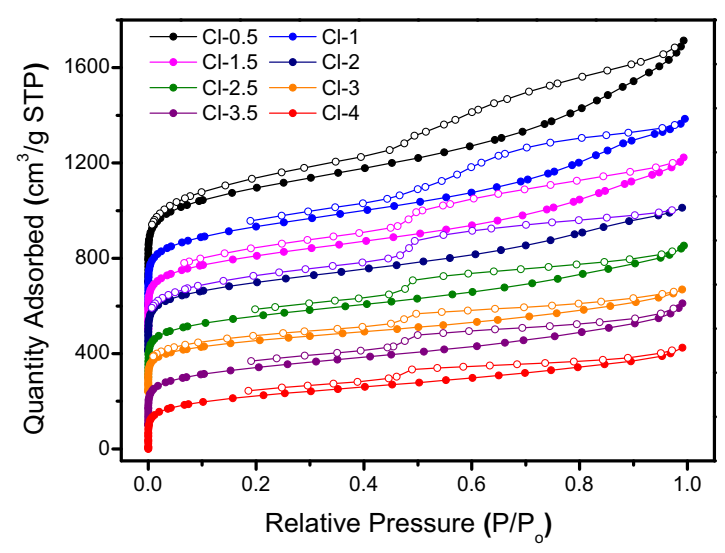

Fig. 1. Nitrogen adsorption (solid circle) and desorption (open circle) isotherms at $77 \mathrm{~K}$ of $\mathrm{HCP}-X$ samples. isotherm according to IUPAC classifications and the initial parts of the adsorption isotherms of all samples show a steep increase in nitrogen gas uptake $\left(p / p_{0}<0.01\right)$, indicating abundant microporous structure $[22,26]$. Compared with other samples, the adsorption isotherms of HCP-0.5 exhibit a remarkable rise and the desorption branch of the hysteresis loop is steeper than the adsorption branch at higher relative pressure $\left(p / p_{0}=0.3-1.0\right)$, indicating that a range of larger mesopores are presented in this polymeric material [27].

Pore size distributions of all polymeric samples are shown in Fig. 2. The most prevalent pores are centered below $2 \mathrm{~nm}$, which indicates that the polymer is predominantly micropore. The peaks at region larger than $2 \mathrm{~nm}$ in pore size distribution demonstrate the existence of mesopore $(2-50 \mathrm{~nm})$ in the polymeric materials. The pore size distribution curves suggest the presence of both micropores and mesopores in all these polymers.

Detailed porosity properties of all polymeric materials prepared are presented in Table 1 . It is clearly observed that by adjusting the monomer to cross-linker ratio, the BET surface areas and pore volumes can be controlled. The BET surface areas, total pore volumes and micropore volumes of samples decrease obviously and the average pore sizes slightly decrease with the increase of FDA amount. The highest BET surface area obtained is up to $1394 \mathrm{~m}^{2} / \mathrm{g}$ for HCP- 0.5 , while HCP-4.0 shows the lowest surface area of $784 \mathrm{~m}^{2} / \mathrm{g}$. The HCP-0.5 sample shows the highest total pore volume $\left(1.55 \mathrm{~cm}^{3} / \mathrm{g}\right)$ and the highest micropore volume $\left(1.01 \mathrm{~cm}^{3} / \mathrm{g}\right)$.

As typical examples, Fig. 3 presents high-resolution SEM images and TEM images of HCP-0.5 and HCP-4.0 samples. High-resolution SEM images (Fig. 3(a) and (b)) show that two samples are composed of an amorphous lump morphology. As reported in literature [21], the lumps are formed by many nanospheres which adhere and accumulate together. The average diameters of the nanospheres of two samples are all less than $100 \mathrm{~nm}$ and the nanoparticle size of HCP-4.0 sample is slightly larger. It is also obvious that the nanospheres of HCP-4.0 sample adhere much closer than HCP-0.5 sample, which may be due to the higher extent of polymerization of the HCP-4.0 sample. TEM images (Fig. 3(c) and (d)) of the two samples further confirm the above results. From the TEM images of two samples we can observe the pores of HCP-0.5 sample and HCP-4.0 sample are disordered. HCP-0.5 sample shows the small and abundant nanospheres (Fig. 3(c)), while the HCP-4.0 sample gives relatively large extent of conglutination and accumulation (Fig. 3(d)). These results are in a good agreement with the observation by high-resolution SEM and nitrogen adsorption techniques. As a typical example, the FT-IR spectrum of HCP-0.5 is

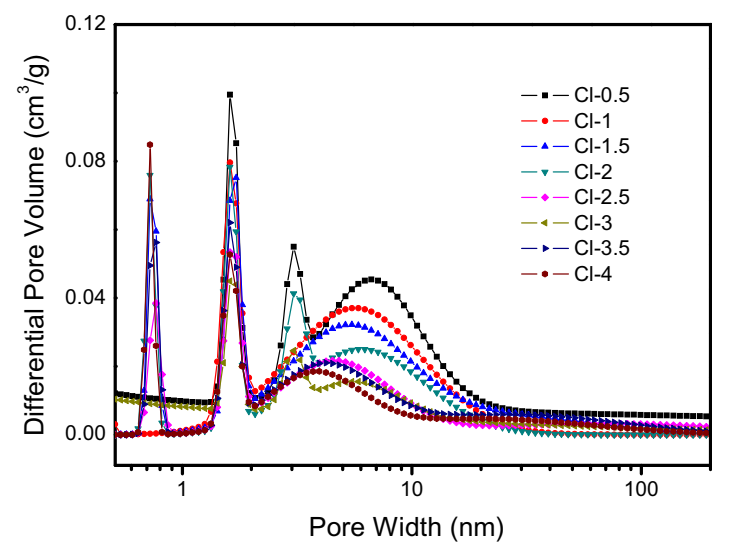

Fig. 2. Pore size distributions calculated using DFT methods (slit pore models, differential pore volumes versus pore width) of samples. 
Table 1

Porous textural properties of HCP-X samples.

\begin{tabular}{lllll}
\hline Sample & $\begin{array}{l}\text { BET surface } \\
\text { area }\left(\mathrm{m}^{2} / \mathrm{g}\right)\end{array}$ & $\begin{array}{l}\text { Average pore } \\
\text { diameter }(\mathrm{nm})\end{array}$ & $\begin{array}{l}\text { Total pore } \\
\text { volume } \\
\left(\mathrm{cm}^{3} / \mathrm{g}\right)\end{array}$ & $\begin{array}{l}\text { Micropore } \\
\text { volume } \\
\left(\mathrm{cm}^{3} / \mathrm{g}\right)\end{array}$ \\
\hline HCP-0.5 & 1394 & 4.4 & 1.55 & 1.01 \\
HCP-1.0 & 1190 & 4.0 & 1.12 & 0.93 \\
HCP-1.5 & 1106 & 4.0 & 1.10 & 0.79 \\
HCP-2.0 & 1001 & 3.7 & 0.93 & 0.75 \\
HCP-2.5 & 913 & 3.7 & 0.84 & 0.62 \\
HCP-3.0 & 843 & 3.6 & 0.75 & 0.53 \\
HCP-3.5 & 837 & 3.6 & 0.70 & 0.47 \\
HCP-4.0 & 784 & 3.3 & 0.66 & 0.48 \\
\hline
\end{tabular}

shown in Fig. 4. The FT-IR spectrum is consistent with the expected networks showing aromatic benzene ring at ca. 1600 and $1660 \mathrm{~cm}^{-1}$, and the peaks at $c a .3030$ and $1450 \mathrm{~cm}^{-1}$ are assigned to the vibrations of $\mathrm{C}-\mathrm{H}$ in $\mathrm{HCP}-0.5$ [28]. The detected absorbed band around $1265 \mathrm{~cm}^{-1}$ in curves is attributed to the wagging vibration of $-\mathrm{CH}_{2} \mathrm{Cl}$ [22]. The TGA curve of HCP- 0.5 is shown in Fig. 5. A small degree of weight loss around the temperature of $150{ }^{\circ} \mathrm{C}$ can be designated to a loss of adsorbed water on sample and the evaporation of residual organic solvents. The temperature of thermal decomposition for HCP-0.5 is greater than $400^{\circ} \mathrm{C}$. This result reveals that HCP- 0.5 adsorbent exhibits a good thermal stability.

\subsection{Static adsorption and desorption behaviors}

It is widely recognized that apparent BET surface area and pore volume are two crucial factors that affect the adsorption capacity of adsorbent. The typical synthesized HCP- 0.5 with a largest BET surface area and total pore volume was selected as a representative polymeric adsorbent to investigate the adsorption behavior for VOCs. The adsorption and desorption isotherms for benzene vapor over HCP-0.5 at 298, 308 and $318 \mathrm{~K}$ are shown in Fig. 6. Attributed to the existence of abundant microporous structure, the adsorption amount of benzene on HCP- 0.5 increases faster at lower pressures.

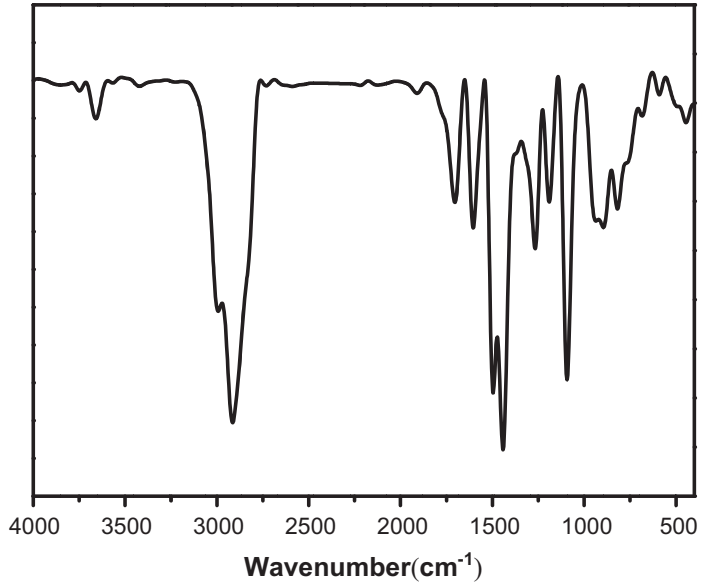

Fig. 4. FT-IR spectrum of HCP-0.5.

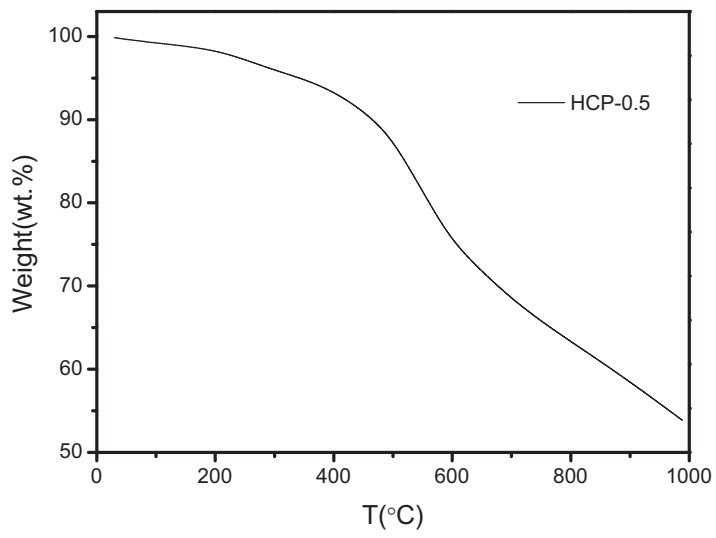

Fig. 5. TGA curve of HCP-0.5.
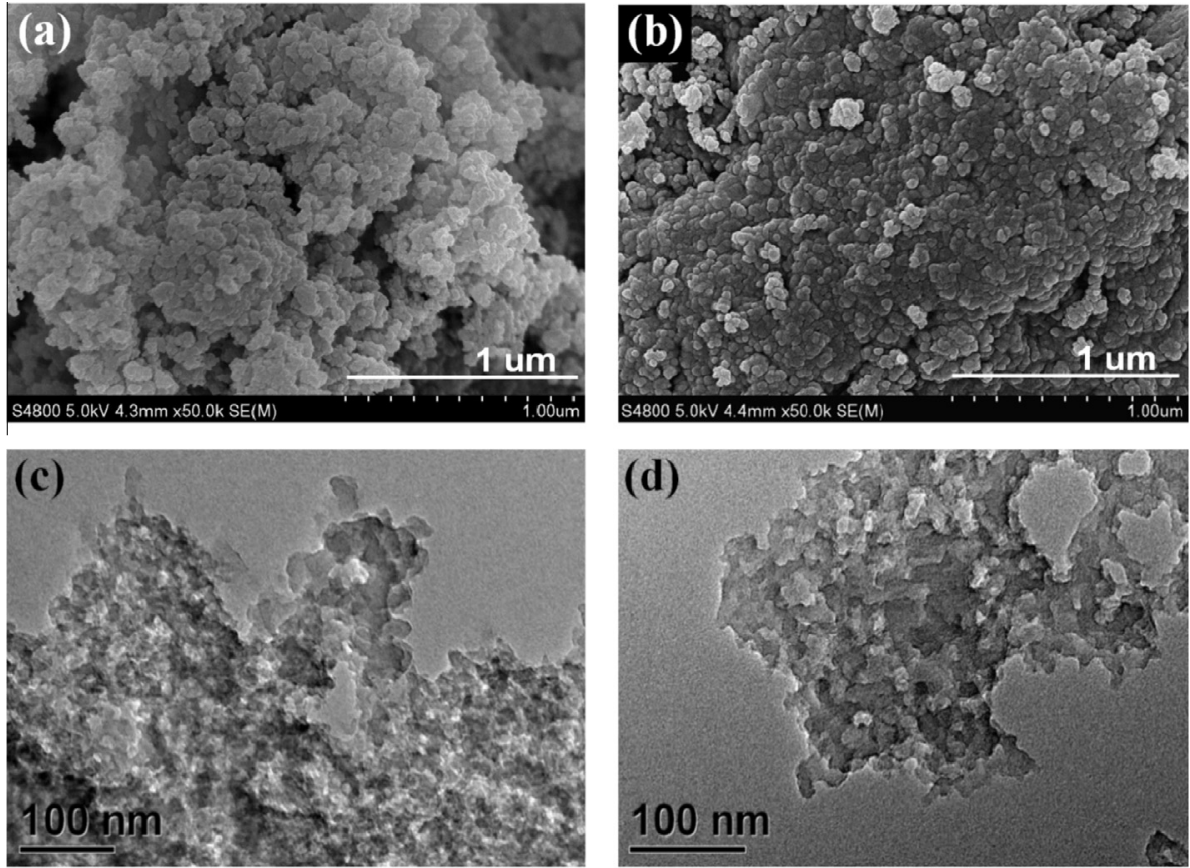

Fig. 3. (a) High-resolution SEM image of HCP-0.5; (b) high-resolution SEM image of HCP-4.0; (c) TEM image of HCP-0.5; (d) TEM image of HCP-4.0 
As shown in Fig. 6, increasing the adsorption temperature from 298 to $318 \mathrm{~K}$ reduces the adsorption capacities of benzene on $\mathrm{HCP}-0.5$, which is consistent with a physisorption mechanism. According to the IUPAC classification, the isotherms of benzene vapor at 298 , 308 and $318 \mathrm{~K}$ are analogous with type II, indicating the monolayer adsorption at lower pressures and the multilayer adsorption at relatively higher pressures. The highest adsorbed amount of benzene on HCP- 0.5 obtained at $298 \mathrm{~K}$ can reach up to $19.16 \mathrm{mmol} \mathrm{g}^{-1}$. The adsorbed amounts for benzene under static conditions over some other adsorbents are collected in Table 2 for comparison [29-32], which demonstrates the adsorption capability for benzene of HCP-0.5 is much higher than many classical pore absorbents reported. Although the adsorption capacity of HCP-1.3 in our previous work [22] is a little bigger than HCP-0.5 due to its greater surface area and pore volume, the simply one-step synthesis method of HCP- 0.5 makes it a dominant position to remove VOCs from air streams.

For comparison, the adsorption property of water vapor on HCP-0.5 sample is also investigated by static measurements. The corresponding adsorption isotherms of benzene and water at three different temperatures $(298,308$ and $318 \mathrm{~K}$ ) are depicted in Fig. 7. According to the IUPAC classification, all the adsorption isotherms of water are of type III, which means the interactions between adsorbate and adsorbent are much smaller than the interactions between adsorbate and adsorbate during the adsorption process. The adsorption isotherm of water at $318 \mathrm{~K}$ exists a sharp increase in the quantity of gas adsorbed up to pressures nearing saturation $\left(p / p_{0}>0.85\right)$ as a result of capillary condensation of water. From Fig. 7, it shows clearly that the adsorption amounts of water on HCP-0.5 at different temperatures are much smaller than the adsorption amounts of benzene, which indicates the hydrophobic surface of HCP-0.5.

\subsection{Virial equation}

Adsorbate-adsorbent interactions can be quantified by comparing the uptakes under specific temperature/pressure conditions, Henry's law constants $\left(K_{H}\right)$ at specific temperatures that is related to an affinity between an adsorbent surfaces and an adsorbed gas molecules and an isosteric enthalpies of adsorption at a zero surface coverage $\left(Q_{s t}, n=0\right)$. The isosteric enthalpy of adsorption at the zero surface coverage is a fundamental measurement of an interaction of species with surfaces [33].

The virial equation can be written in the form [34]

$\ln \left(\frac{n}{p}\right)=A_{0}+A_{1} n+A_{2} n^{2}+\ldots$

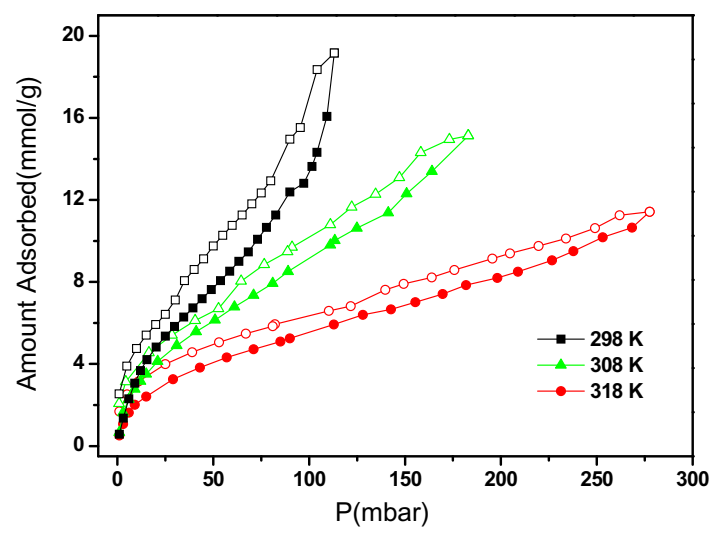

Fig. 6. Adsorption (solid circle) and desorption (open circle) isotherms of benzene on HCP-0.5 at 298,308 and $318 \mathrm{~K}$.
Table 2

Comparison of adsorption capacities of HCP-0.5 and other adsorbents for adsorption of benzene.

\begin{tabular}{ll}
\hline Adsorbent & Adsorption capacity $(\mathrm{g} / \mathrm{g})$ \\
\hline HCP-0.5 & 1.49 \\
HCP-1.3 [22] & 1.58 \\
Silica gel [29] & 0.65 \\
TMES-aerogel [29] & 0.71 \\
Activated carbon [30] & 0.73 \\
Hydrophobic aerogels [31] & 0.49 \\
Monolithic carbon aerogel [32] & 0.84 \\
\hline
\end{tabular}

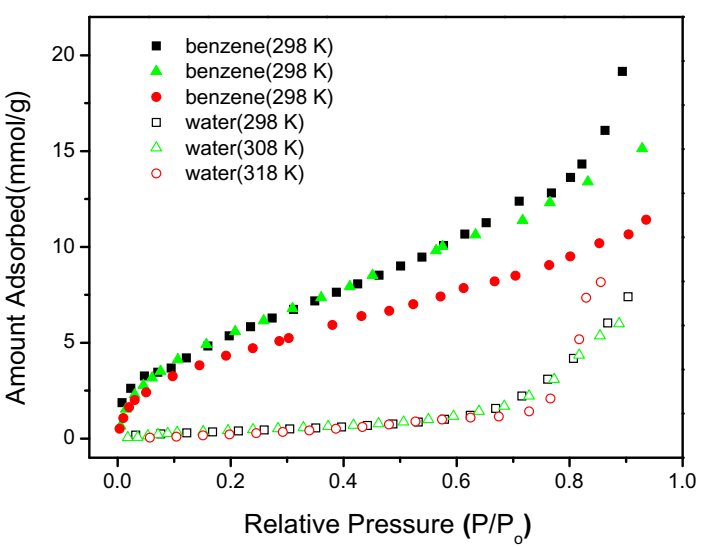

Fig. 7. Adsorption isotherms of benzene and water on HCP-0.5 at 298, 308 and $318 \mathrm{~K}$.

where $n$ is the amount adsorbed $\left(\mathrm{mol} \mathrm{g}^{-1}\right)$ at pressure $p(\mathrm{~Pa})$. The first virial coefficient $A_{0}\left(\ln \left(\mathrm{mol} \mathrm{g}^{-1} \mathrm{~Pa}^{-1}\right)\right)$ is related to the Henry's Law constant $K_{H}$. At zero surface coverage the virial equation reduces to Henry's Law; hence, $K_{H}=\exp \left(A_{0}\right)$. The values of the first virial coefficient $\left(A_{0}\right)$ reflect adsorbate/adsorbent interaction, whereas the second virial parameter $\left(A_{1}\right)$ is a function of adsorbate/adsorbate interactions. In this study, analysis of the data showed that the $A_{2}$ and higher terms in the virial equation can be ignored under conditions of low surface coverage.

Fig. 8 shows the virial graphs for benzene (Fig. 8(a)) and water (Fig. 8(b)) adsorption on HCP-0.5 at different temperatures (298, 308 and $318 \mathrm{~K})$. Linear graphs of $\ln (n / p)$ versus $n$ for all the adsorption studied can be obtained at low surface coverage. The virial graphs of benzene at 298, 308 and $318 \mathrm{~K}$ are similar and distinguished with the virial graphs of water, obviously.

The virial parameters obtained from these graphs are shown in Table $3 . A_{0}$ for benzene and water become more negative as the temperature increases, it is a result of weaker adsorbate-adsorbent interactions and this is consistent with the physisorption mechanism. $K_{H}$ is dependent on the interaction between the adsorbed molecule and the adsorbent surface. From Table 3, it is obvious that the $K_{H}$ values for benzene and water at 298,308 and $318 \mathrm{~K}$ are in the order of benzene $(298 \mathrm{~K})>$ benzene $(308 \mathrm{~K})>$ benzene $(318 \mathrm{~K})>>$ water $(298 \mathrm{~K})>$ water $(308 \mathrm{~K})>$ water $(318 \mathrm{~K})$.

The order is consistent with the physisorption mechanism. It is obvious that Henry constants $\left(K_{H}\right)$ for benzene are much greater than for water, due to the stronger adsorbate-adsorbent interactions between benzene and polymeric adsorbent, implying a good selectivity for benzene adsorption on polymeric adsorbent in humid environment.

\subsection{Adsorption and desorption kinetics}

A number of kinetic models for diffusion of molecules into polymeric adsorbent have been used. Linear driving force (LDF) model, 

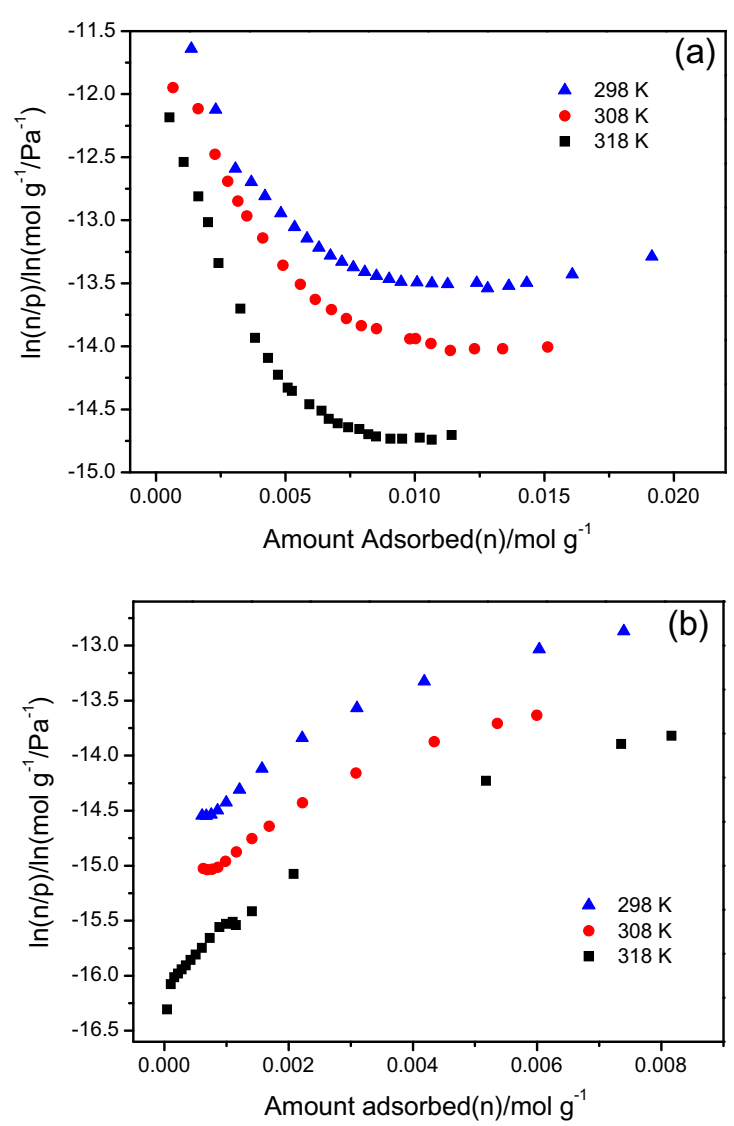

Fig. 8. Virial graphs for the adsorption of (a) benzene and (b) water on HCP-0.5 at 298, 308 and $318 \mathrm{~K}$.

one of the most widely used uptake rate approximation, provides satisfactory descriptions, in most cases, of the adsorption and desorption kinetics of the various gases/vapors on porous materials depending on the adsorptive and experimental conditions. In the present work, we selected the LDF model to simulate the adsorption-desorption kinetics of benzene over HCP-0.5 sample.

The LDF model for adsorption is described by the following equation [35]:

$\frac{M_{t}}{M_{e}}=1-e^{-k t}$

where $M_{t}$ is mass uptake at time $t, M_{e}$ is mass uptake at equilibrium and $k$ is the kinetic rate constant.

For a desorption process, a corresponding specific equation can be described as follows:

$\frac{M_{t}}{M_{e}}=e^{-k t}-1$

where $M_{t}$ is the desorbed amount at time $t, M_{e}$ is the equilibrium desorbed amount for the given pressure increment, and $k$ is the desorbed rate constant.
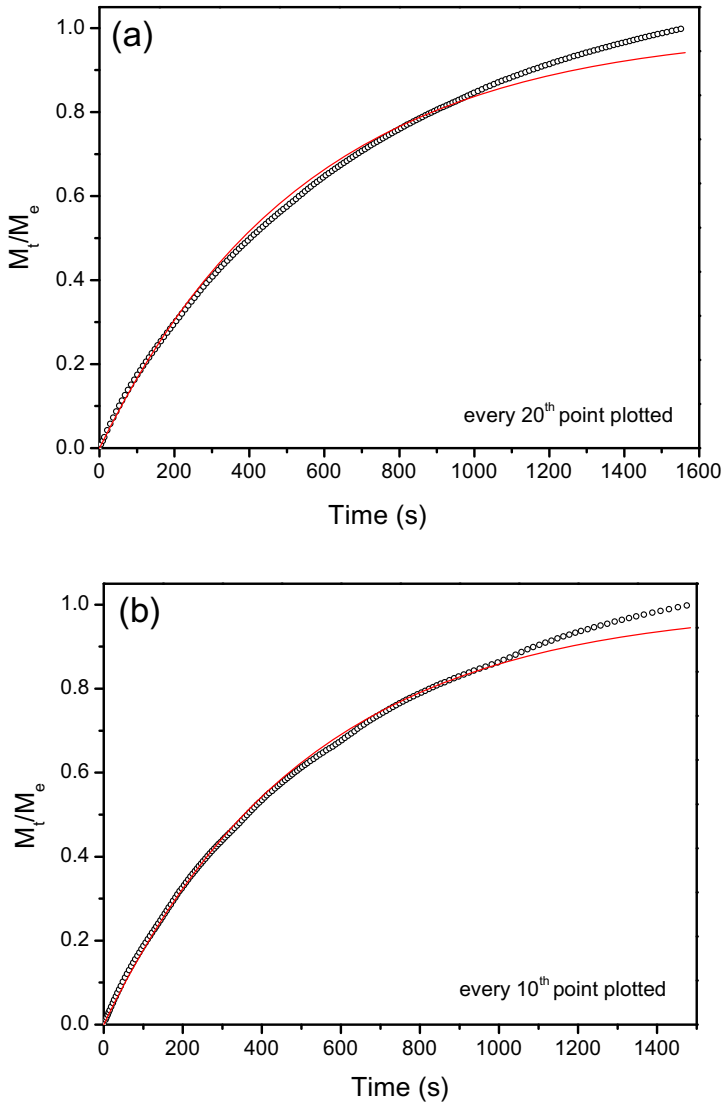

Fig. 9. Variation of $M_{t} / M_{e}$ versus time for benzene and water adsorption on HCP-0.5 at $298 \mathrm{~K}$. (a) Benzene: $58.15-58.60 \mathrm{mbar}\left(p / p_{0}=0.4593-0.4629\right)$; (b) water: 21.20 $21.27 \mathrm{mbar}\left(p / p_{0}=0.6667-0.6689\right)$.

Typical diagrams of $M_{t} / M_{e}$ versus time $t$ for the adsorption of benzene and water on HCP-0.5 and the desorption of benzene and water on HCP-0.5 are shown in Figs. 9 and 10. Each diagram shows that the adsorption behaviors of benzene and water on HCP- 0.5 obey the LDF model and represents pressure increments in a different pressure region to prove that the model holds regardless of the position on the isotherm, indicating that diffusion through a barrier at the pore entrance is the rate-determining step during a adsorption process. The desorption kinetics that is similar to the adsorption kinetics, comply the LDF model.

\subsection{Effect of relative humidity on dynamic adsorption}

A breakthrough curve measurement is a direct method to investigate the dynamic adsorption behavior of VOCs. The dynamic adsorption experiments of benzene on HCP- 0.5 under dry condition and humid condition $(80 \% \mathrm{RH})$ were carried out using the method described in the present paper. To elucidate quantitatively the dynamic adsorption behavior of benzene and the effect of

Table 3

Fitting parameters of virial equation for adsorption of benzene and water on HCP-0.5 at 298, 308 and $318 \mathrm{~K}$.

\begin{tabular}{|c|c|c|c|c|c|}
\hline \multirow[t]{2}{*}{ Adsorbate } & \multirow[t]{2}{*}{ Temperature (K) } & \multicolumn{3}{|l|}{ Virial parameters } & \multirow[t]{2}{*}{ Henry constants $K_{H}\left(\times 10^{-6}\right)$} \\
\hline & & $A_{0}$ & $A_{1}$ & $R^{2}$ & \\
\hline Benzene & $\begin{array}{l}298 \\
308 \\
318\end{array}$ & $\begin{array}{l}-11.548 \pm 0.094 \\
-11.681 \pm 0.058 \\
-11.932 \pm 0.048\end{array}$ & $\begin{array}{l}-331.85 \pm 21.433 \\
-411.43 \pm 17.491 \\
-636.73 \pm 18.194\end{array}$ & $\begin{array}{l}0.934 \\
0.985 \\
0.992\end{array}$ & $\begin{array}{l}9.655 \\
8.453 \\
6.577\end{array}$ \\
\hline Water & $\begin{array}{l}298 \\
308 \\
318\end{array}$ & $\begin{array}{l}-14.886 \pm 0.027 \\
-15.385 \pm 0.023 \\
-16.109 \pm 0.027\end{array}$ & $\begin{array}{l}524.409 \pm 21.479 \\
499.402 \pm 21.134 \\
562.601 \pm 32.282\end{array}$ & $\begin{array}{l}0.996 \\
0.997 \\
0.990\end{array}$ & $\begin{array}{l}0.343 \\
0.208 \\
0.101\end{array}$ \\
\hline
\end{tabular}



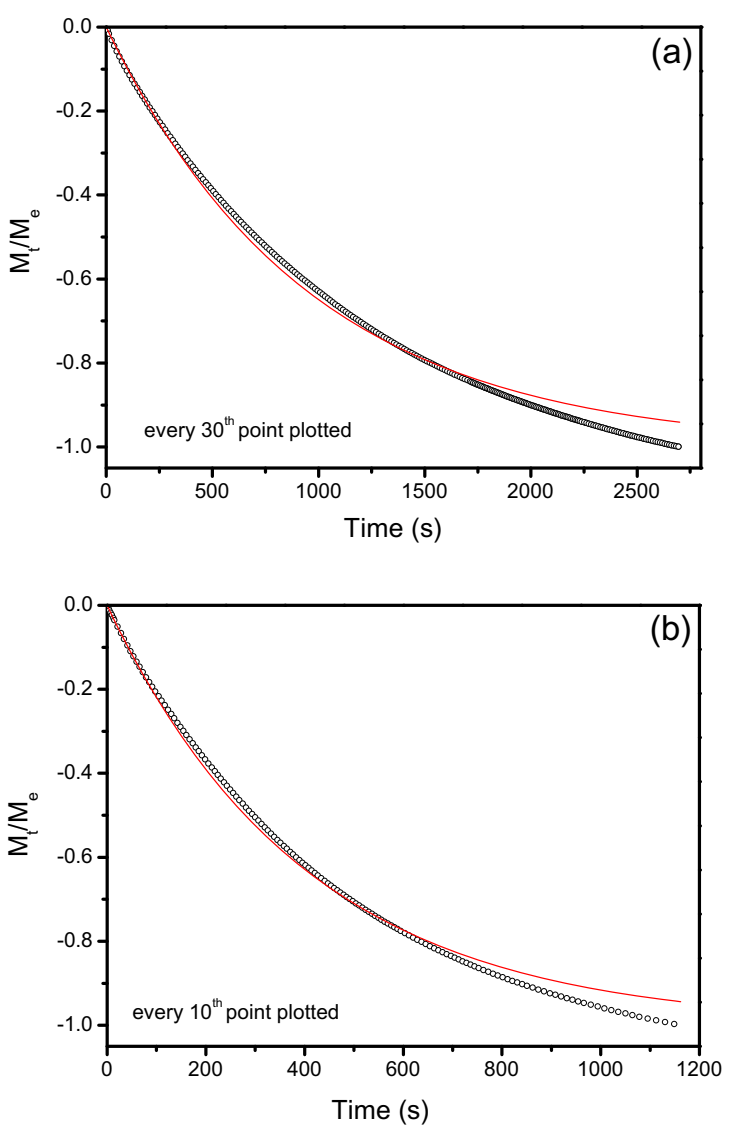

Fig. 10. Variation of $M_{t} / M_{e}$ versus time for benzene and water desorption on HCP0.5 at $298 \mathrm{~K}$. (a) Benzene: $30.15-30.49 \mathrm{mbar}\left(p / p_{0}=0.2381-0.2408\right)$; (b) water: 19.89-19.77 $\mathrm{mbar}\left(p / p_{0}=0.6255-0.6217\right)$.

relative humidity on the adsorption, the breakthrough curves were fitted using the Yoon and Nelson model ( $\mathrm{Y}-\mathrm{N}$ model). The $\mathrm{Y}-\mathrm{N}$ equation is expressed as the following [36].

$t=\tau+\frac{1}{k^{\prime}} \ln \frac{C_{b}}{C_{i}-C_{b}}$

where $C_{i}$ and $C_{b}$ are inlet and outlet concentration of adsorbate $\left(\mathrm{mg} \mathrm{L}^{-1}\right), t$ is the adsorption time $(\mathrm{min}), k^{\prime}$ is the rate constant $\left(\min ^{-1}\right)$, and $\tau$ is the time required for $50 \%$ adsorbate breakthrough (min).

Fig. 11 shows breakthrough curves of benzene under dry and humid conditions $(80 \% \mathrm{RH})$ in hyper-cross-linked polymer bed at $298 \mathrm{~K}$. It is obvious that the breakthrough curves of benzene under dry conditions and wet conditions on HCP- 0.5 are well fitted by the $\mathrm{Y}-\mathrm{N}$ model. It is shown clearly that the presence of water changes a little the breakthrough curve when the relative humidity is $80 \%$.

Table 4 summaries the calculated adsorption capacities and breakthrough time of benzene on HCP- 0.5 based on the Y-N equation. The breakthrough time is calculated as the time at which the concentration of benzene in the outlet is $5 \%$ of the inlet concentration. From Table 4, it indicated that the breakthrough time decreased when water vapor exists and the decrease in the breakthrough time is less than $15 \%$. Under dry condition, the breakthrough time of benzene on HCP-0.5 is $77.83 \mathrm{~min}$, with a relatively low value of $66.41 \mathrm{~min}$ under the $80 \%$ relative humidity wet condition. The decrease in breakthrough time is due to the water adsorbed may hinder the diffusion of benzene in the pores. Due to hydrophobic property of HCP-0.5, the interactions between the water and the surface of the adsorbent are weaker than that between VOCs and the surface of the adsorbent, so the water

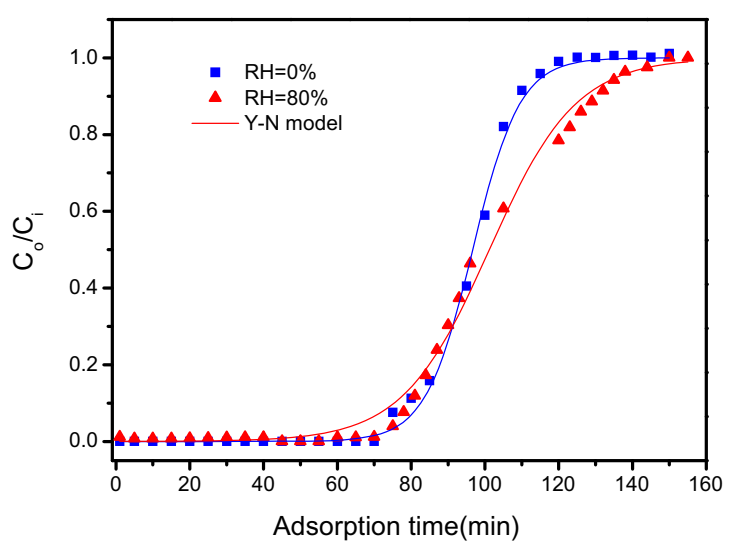

Fig. 11. Breakthrough curves of benzene adsorption on HCP-0.5 under dry and humid concentrations at $298 \mathrm{~K}$

Table 4

Breakthrough characteristics and dynamic adsorption capacity of benzene adsorption on HCP- 0.5 .

\begin{tabular}{rlllll}
\hline $\begin{array}{r}\text { RH } \\
(\%)\end{array}$ & $\begin{array}{l}\text { Breakthrough time } \\
(\mathrm{min})\end{array}$ & $\begin{array}{l}\text { Equilibrium time } \\
(\mathrm{min})\end{array}$ & $\begin{array}{l}Q \\
\left(\mathrm{mmol} \mathrm{g}^{-1}\right)^{\mathrm{a}}\end{array}$ & $k^{\mathrm{b}}$ & $R^{2}$ \\
\hline 0 & 77.83 & 111.15 & 1.70 & 0.16 & 0.998 \\
80 & 66.41 & 115.60 & 1.46 & 0.08 & 0.995 \\
\hline a & & & &
\end{tabular}

a Dynamic adsorption amount at $298 \mathrm{~K}$.

b Rate constant calculated by Y-N model.

adsorbed via pore filling can be displaced by benzene under the $80 \%$ relative humidity wet condition [37]. The dynamic adsorption amount of benzene on $\mathrm{HCP}-0.5$ under $80 \%$ relative humidity reaches $86 \%$ of the corresponding value under dry condition as listed in Table 4, which indicates that high concentration of water vapor in a gaseous mixture will not significantly reduce the adsorption capacity of benzene on HCP-0.5. This finding further proves that the HCP- 0.5 adsorbent has a hydrophobic surface property.

\section{Conclusions}

In summary, a new hyper-cross-linked polymer, hydrophobic HCPs, was successfully synthesized via one-step Friedel-Crafts alkylation reaction using benzyl chloride as a monomer, FDA as a cross-linker and $\mathrm{FeCl}_{3}$ as a catalyst. It is found that an HCP having a good hydrophobicity with high surface area and pore volume was formed under the investigated conditions. By adjusting benzyl chlorine to FDA molar ratio, the HCP-0.5 sample having a high surface area of $1394 \mathrm{~m}^{2} / \mathrm{g}$, a large pore volume of $1.55 \mathrm{~m}^{3} / \mathrm{g}$ and micro-mesopore structure was obtained. The static adsorption of benzene and water vapor was demonstrated over HCP-0.5 sample. The results indicated that the static adsorption amount of benzene obtained at $298 \mathrm{~K}$ is much greater than most of other classical adsorbents reported in literature. Henry' law constant of HCP-0.5, calculated from virial equation, proved that the HCP-0.5 exhibited a good hydrophobicity. The dynamic adsorption results indicated that high concentration water vapor in benzene had little effect on the adsorption capacity of benzene on HCP-0.5. The dynamic adsorption amount of benzene on $\mathrm{HCP}-0.5$ under $80 \%$ relative humidity can reach $86 \%$ of the corresponding value under dry condition and the breakthrough times are almost unchanged, which revealed that HCP-0.5 sample could exhibit high selectivity for the adsorption of benzene when water vapor coexists. The 
excellent adsorption performances of HCP-0.5 make this kind of material a potential candidate in removing VOCs, especially under humid conditions.

\section{Acknowledgments}

This work was financially supported by the National Natural Science Foundation of China $(21327011,21306111,21337003)$, the National High Technology Research and Development Program of China (No. 2012AA063101), the Shaanxi Innovative Team of Key Science and Technology (2012KCT-21, 2013KCT-17), and the Program for Changjiang Scholars and Innovative Research Team in University (IRT_14R33).

\section{References}

[1] F.I. Khan, A.K. Ghoshal, Removal of volatile organic compounds from polluted air, J. Loss Prev. Process Ind. 13 (6) (2000) 527-545.

[2] D. Debasish, G. Vivekanand, V. Nishith, Removal of volatile organic compound by activated carbon fiber, Carbon 42 (14) (2004) 2949-2962.

[3] E.N. Ruddy, L.A. Carroll, Select the best VOC control strategy, Chem. Eng. Prog. 89 (7) (1993) 28-35.

[4] A. Reguer, S. Sochard, C. Hort, V. Platel, Measurement and modelling of adsorption equilibrium, adsorption kinetics and breakthrough curve of toluene at very low concentrations on to activated carbon, Environ. Technol. 32 (7) (2011) 757-766.

[5] V.K. Gupta, N. Verma, Removal of volatile organic compounds by cryogenic condensation followed by adsorption, Chem. Eng. Sci. 57 (14) (2002) 2679 2696.

[6] G.O. Wood, A review of the effects of covapors on adsorption rate coefficients of organic vapors adsorbed onto activated carbon from flowing gases, Carbon 40 (5) (2002) 685-694.

[7] L. Li, S.Q. Liu, J.X. Liu, Surface modification of coconut shell based activated carbon for the improvement of hydrophobic VOC removal, J. Hazard. Mater. 192 (2) (2011) 683-690.

[8] J.H. Tsai, H.M. Chiang, G.Y. Huang, H.L. Chiang, Adsorption characteristics of acetone, chloroform and acetonitrile on sludge-derived adsorbent, commercial granular activated carbon and activated carbon fibers, J. Hazard. Mater. 154 (1-3) (2008) 1183-1191.

[9] M.J. Ruhl, Recover VOCs via adsorption on activated carbon, Chem. Eng. Prog. 89 (7) (1993) 37-41.

[10] R.A. Zerbonia, C.M. Brockmann, P.R. Peterson, D. Housley, Carbon bed fires and the use of carbon canisters for air emissions control on fixed-roof tanks, J. Air Waste Manage. Assoc. 51 (12) (2001) 1617-1627.

[11] D. Kaplan, I. Nir, L. Shmueli, Effects of high relative humidity on the dynamic adsorption of dimethyl methylphosphonate (DMMP) on activated carbon, Carbon 44 (15) (2006) 3247-3254.

[12] N. Qi, W.S. Appel, M.D. LeVan, J.E. Finn, Adsorption dynamics of organic compounds and water vapor in activated carbon beds, Ind. Eng. Chem. Res. 45 (7) (2006) 2303-2314.

[13] E.J. Simpson, W.J. Koros, R.S. Schechter, An emerging class of volatile organic compound sorbents: Friedel-Crafts modified polystyrenes. 2. Performance comparison with commercially-available sorbents and isotherm analysis, Ind. Eng. Chem. Res. 35 (12) (1996) 4635-4645.

[14] M.P. Baya, P.A. Panayotis, V.A. Davankov, Evaluation of a hyper-cross-linked polystyrene, MN-200, as a sorbent for the preconcentration of volatile organic compounds in air, J. Assoc. Off. Anal. Chem. Int. 83 (3) (2000) 579-583.

[15] P. Liu, C. Long, Q.F. Li, H.M. Qian, A.M. Li, Q.X. Zhang, Adsorption of trichloroethylene and benzene vapors onto hyper-cross-linked polymeric resin, J. Hazard. Mater. 166 (1) (2009) 46-51.
[16] C. Long, Q.F. Li, Y. Li, Y. Liu, A.M. Li, Q.X. Zhang, Adsorption characteristics of benzene-chlorobenzenevapor on hyper-cross-linked polystyrene adsorbent and apilot-scale application study, Chem. Eng. J. 160 (2) (2010) 723-728.

[17] N.B. Mckeown, P.M. Budd, Exploitation of intrinsic microporosity in polymerbased materials, Macromolecules 43 (12) (2010) 5163-5176.

[18] T. Ben, H. Ren, S. Ma, D. Cao, J. Lan, X. Jing, F. Deng, J.M. Simmons, S. Qiu, G. Zhu, Targeted synthesis of a porous aromatic framework with high stability and exceptionally high surface area, Angew. Chem. 121 (50) (2009) 9621-9624.

[19] C. Weder, Hole control in microporouspolymers, Angew. Chem. Int. Ed. 47 (3) (2008) 448-450

[20] J.X. Jiang, F. Su, A. Trewin, C.D. Wood, H. Niu, J.T. Jones, Y.Z. Khimyak, A.I. Cooper, Synthetic control of the pore dimension and surface area in conjugated microporous polymer and copolymer networks, J. Am. Chem. Soc. 130 (24) (2008) 7710-7720.

[21] B. Li, R. Gong, W. Wang, X. Huang, W. Zhang, H. Li, C. Hu, B. Tan, A new strategy to microporous polymers: knitting rigid aromatic building blocks by external cross-linker, Macromolecules 44 (8) (2011) 2410-2414.

[22] G. Wang, B.J. Dou, J.H. Wang, W.Q. Wang, Z.P. Hao, Adsorption properties of benzene and water vapor on hyper-cross-linked polymers, RSC Adv. 3 (43) (2013) 20523-20531.

[23] J.H. Wang, G. Wang, W.Q. Wang, Z.S. Zhang, Z.T. Liu, Z.P. Hao, Hydrophobic conjugated microporous polymer as a novel adsorbent for removal of volatile organic compounds, J. Mater. Chem. A 2 (34) (2014) 14028-14037.

[24] X.B. Zhao, B. Xiao, A.J. Fletcher, K.M. Thomas, Hydrogen adsorption on functionalized nanoporous activated carbons, J. Phys. Chem. B 109 (18) (2005) 8880-8888.

[25] Q. Hu, J.J. Li, Z.P. Hao, L.D. Li, S.Z. Qiao, Dynamic adsorption of volatile organic compounds on organofunctionalized SBA-15 materials, Chem. Eng. J. 149 (1-3) (2009) 281-288.

[26] R. Dawson, A.I. Cooper, D.J. Adams, Nanoporous organic polymer networks, Prog. Polym. Sci. 37 (4) (2012) 530-563.

[27] K.S.W. Sing, Reporting physisorption data for gas/solid systems with special reference to the determination of surface area and porosity, Pure Appl. Chem. 57 (4) (1985) 603-619.

[28] Y. Luo, S. Zhang, Y. Ma, W. Wang, B. Tan, Microporous organic polymers synthesized by self-condensation of aromatic hydroxymethyl monomers, Polym. Chem. 4 (4) (2013) 1126-1131.

[29] J.A. Quevedo, G. Patel, R. Pfeffer, Removal of oil from water by inverse fluidization of aerogels, Ind. Eng. Chem. Res. 48 (1) (2009) 191-201.

[30] A.J. Fletcher, Y. Yüzak, K.M. Thomas, Adsorption and desorption kinetics for hydrophilic and hydrophobic vapors on activated carbon, Carbon 44 (5) (2006) 989-1004.

[31] D. Wang, E. McLaughlin, R. Pfeffer, Y.S. Lin, Adsorption of organic compounds in vapor, liquid, and aqueous solution phases on hydrophobic aerogels, Ind. Eng. Chem. Res. 50 (21) (2011) 12177-12185.

[32] J.C. Moreno-Pirajan, L. Giraldo, Adsorption of benzene and phenolic derivatives in monolithic carbon aerogels, Chem. Sci. Trans. 2 (S1) (2013) 251-261.

[33] J.G. Bell, X. Zhao, Y. Uygur, K.M. Thomas, Adsorption of chloroaromatic models for dioxins on porous carbons: the influence of adsorbate structure and surface functional groups on surface interactions and adsorption kinetics, J. Phys. Chem. C 115 (6) (2011) 2776-2789.

[34] J.H. Cole, D.H. Everett, C.T. Marshall, A.R. Paniego, J.C. Powl, F. RodriguezReinoso, Thermodynamics of high temperature adsorption of some permanent gases by porous carbons, J. Chem. Soc., Faraday Trans. 1 (70) (1974) 21542169.

[35] B.J. Dou, J.J. Li, Y.F. Wang, H.L. Wang, C.Y. Ma, Z.P. Hao, Adsorption and desorption performance of benzene over hierarchically structured carbonsilica aerogel composites, J. Hazard. Mater. 196 (2011) 194-200.

[36] Y.H. Yoon, J.H. Nelson, Application of gas adsorption kinetics I. Atheoretical model for respirator cartridge service life, Am. Ind. Hyg. Assoc. J. 45 (8) (1984) 509-516.

[37] C. Long, P. Liu, Y. Li, A. Li, Q. Zhang, Characterization of hydrophobic hypercross-linked polymer as an adsorbent for removal of chlorinated volatile organic compounds, Environ. Sci. Technol. 45 (10) (2011) 4506-4512. 